\title{
Chapter 3 \\ Line Managers as Work Professionals in the Era of Workplace Health Professionalization
}

\author{
Pascal Ughetto
}

\begin{abstract}
Constructing rules for work that foster both health and safety and efficient production entails, in many organisations, the introduction of procedures, tools and techniques implemented by specialists. The purpose of this is to combat the amateur practices and lack of expertise supposedly found not only amongst employees, but also in their managers. This chapter argues that, on the contrary, field managers possess knowledge about working conditions and are actors who are necessarily involved in organising those conditions as well as the work of their teams. In so doing, they protect employees from or expose them to the real and varying circumstances of work. This is the role that needs to be reinforced in order for safety rules to become a real part of work cultures and working practices. However, the forms of power in organisations increasingly limit the recognition of this expertise in the work of managers. The chapter advocates the importance of giving managers power to set situated organisational rules, instead of making these the exclusive prerogative of central management departments.
\end{abstract}

Keywords Middle management $\cdot$ Organisational rules $\cdot$ Power

\subsection{Introduction}

In the last 15 years or so, the increasing salience of issues of workplace health, safety and working conditions has led to systematic efforts to tackle these questions within companies. This has prompted the development of management processesprocedures, tools, techniques - and the use of specialists claiming expertise in these fields, i.e. both an understanding (even scientific knowledge) of these subjects and the mastery of the tools associated with them: professionals in industrial risk, in the prevention of psychosocial problems, etc. The article examines this professional construction of the domain of workplace health and safety and working conditions:

\footnotetext{
P. Ughetto $(\square)$

Université Paris-Est, Paris, France

e-mail: pascal.ughetto@u-pem.fr

(C) The Author(s) 2018

C. Bieder et al. (eds.), Beyond Safety Training, Safety Management,

https://doi.org/10.1007/978-3-319-65527-7_3
} 
it argues that the professional space of the specialists is in tension, or even in competition, with that of middle managers or field managers, who do not necessarily enjoy the same recognition in these matters as the specialists. However, it can be argued that the role of these middle managers is crucial, or even that they should be the cornerstone of corporate workplace health and safety policies. It is important to promote their role in organising the work of the staff they manage.

Based on field studies that we conducted on workplace health and safety in a variety of sectors (supermarkets, public housing bodies, hospitals, French Ministry of Finance, etc.), we have developed the following argument: as advanced by the other authors in this book, in order to promote working conditions that are safe and protect the physical and mental health of workers, it is crucial to create professional cultures in which the rules of work are constantly updated and pertinent to the realities and variability of the practical situations encountered. In this, managers play a key role: accountable for the organisational rules and required to achieve targets for production and economic efficiency, the challenge they face is to maintain a balance between these targets and rules on the one hand, and professional cultures on the other, in order to consolidate organisational rules that are also health and safety rules. What is crucial is the way they interpret their role or are encouraged to interpret it: as agents for the local "implementation" of centrally-decided rules, or conversely as autonomous actors with the capacity to adjust these central rules to the constraints and challenges of practical situations encountered by staff, and therefore to professional cultures? Workplace health and safety therefore critically reflect the choices companies make and the power relations within them. In companies where the power of the "official" specialists dominates, central rules are very likely to be forced on field managers with no leeway to make them significant in actual working cultures. The result is to challenge the legitimacy of these managers as pivotal agents of work policies. Companies may be tempted by this approach, which has immediate clarity in terms of the assignment of responsibilities and accountability, and in short-term economic terms. Another approach, in appearance more costly, but actually more productive, is one that asserts the powers of field managers to manage the organisation of work in their "perimeter" and, to this end in particular, to encourage conversations and discussions within communities of practice and the adjustment of organisational rules.

\subsection{Professionalizing Workplace Health and Safety?}

Awareness of work and working conditions has made a comeback in the last fifteen years or so. This has reinforced a trend towards the construction of work as a public problem and has boosted the production of legal regulations, collective bargaining on these issues and action by companies to prevent work-related risks. The conception and implementation of these actions has encouraged the emergence of specialists who, individually and collectively, have built their career and research 
around what they believe to be an accurate and serious recognition of the problems and expertise that these entail. This has coincided with the development of specialised management processes focusing on the significant technical and legal facets of these matters, and the use of specialists (in psychosocial risks, industrial risks, etc.); in other words, with the professionalization of workplace health and safety, in the sense that this issue is seen as one that should no longer be left to amateurs, but entrusted to people with expert knowledge, specialists in the field. However, there is nothing immediate, technical or neutral about the tackling of work-related issues. This activity is a social construct, equally reflecting the dynamics of the way these questions are constructed as relating to problems that the actors or a sufficient number of them agree to recognise as real, institutional dynamics that encourage the management of these issues and guide the ways they are tackled, and the dynamics of the production of responses (legal texts, negotiated agreements, instruments...). These responses themselves reflect professional dynamics: how professional groups address these questions and participate in the formulation of the problems and the development of the solutions, or indeed claim to be those most capable of implementing those solutions.

For all these reasons, the term professionalization seems applicable, but its use is not straightforward. Its meaning varies considerably from one country to another. The social construction of what are called instituted professions, in the strongest sense of the term, follows different trajectories, with the result that the same activities are not always fully recognised as the attributes of a profession (Wilensky 1964; Neal and Morgan 2000). However, the question here is whether all the actions required to foster health and safety at work must necessarily entail specialist knowledge and the techniques specialists may propose, as experts external to the work activities concerned, or whether instead, one should resist granting excessive autonomy to this knowledge and these techniques. With regard to the position argued in this chapter, the more concrete issue is the potential tension between specialists who claim to be official professionals in this domain and the middle managers who could assert their own standing as professionals with regards to the working challenges of their staff.

If the term professionalization has its uses in this regard, it is because it can cover a multiplicity of meanings, even in a given country and language. It can have at least three definitions, all of which show that this professional status is less a matter of fact than the result of efforts to obtain recognition for a distinct status: successful for some groups, unsuccessful for others, even though they all seek for such a recognition. Professionalization can thus be defined as:

- establishment of a professional group, with its own territory (a jurisdiction), access to which is confined to its members. These members possess prerogatives based on peer-validated expertise; the specialists we are concerned with here probably do not possess all the attributes of a profession, but lay claim to scientific ethics and knowledge in order to persuade others to recognise such a status; 
- emergence of specialist professions, proliferation of individuals and of structures equipped with rules to apply in order to do things efficiently, economically, without risks, and therefore differently from amateurs (who are suspected of doing things uneconomically, inadequately or riskily); what is important here is the contrast with amateur action, which is precisely what the specialists who concern us here seek to stress;

- familiarity with an activity, day-to-day practice of an activity, whereby it is claimed as a profession within which the self-reflective practitioner is constituted as an expert. This is the idea that, even for the most apparently simple activities, in a job or in another sphere of day-to-day life, being a novice is characterised by the difficulty of coping with situations that are at first sight quite uncomplicated and that dealing with the activity on a daily basis leads to the development of a capacity which is simultaneously a skilled practice and a knowledge of situations (Gordon et al. 1999). This is quite close to what ethnomethodology reveals about the challenge and the difficulty of dealing competently with ordinary situations.

In the transition from one of these definitions to another, the term ceases to be restricted to groups that have succeeded in having an exceptional status recognised by others, and it becomes apparent that there are other groups, which have not made this kind of social effort or have failed to complete it, whose members nevertheless believe, deep down, that they are in reality specialists and deserve to be recognised and listened to as such. What Jan Hayes writes about professionals:

Whilst the term 'professional' and 'professions' are implicated in a fairly tangled and unruly web of usage, the characteristics of professionals include being bound by a code of ethical conduct in addition to technical and/or commercial standards and being able to exercise experienced judgement in specific cases, rather than relying completely on application of general rules (Hayes 2014)

is a claim that can reasonably be made by safety specialists; but others (workers, technicians, managers, who are the target of their instructions) would also, no doubt, wish to emphasise that they do not work without ethical standards, technical precision or the exercise of experienced judgement.

All this should undoubtedly be seen as the discursive and practical strategy of a relatively homogeneous group possessing a degree of unity in its representation of reality and its activities. The issue is less about dividing reality between professions that are "really" definable as such, and others that are not, than about understanding the efforts made by groups that are constituted to varying degrees to achieve recognition for the value of their professional activity and their contributions, efforts in which some groups are more successful than others. From the perspective of symbolic interactionism, it is not possible to decide definitively and objectively which groups should be recognised as professions and which should not. Instead, there are professional dimensions that run through all the groups, but their specific nature as a group varies and these forms of professionalization also differ in their robustness. There are struggles, both individual and collective, of varying intensity, to achieve recognition for the activity practised, for its value to the common good 
and for its value as a complex and expert activity, and to be awarded a status which differs from that of other activities and professional groups.

From this perspective, there exists a whole continuum and a possible link with the fact that even individuals unfavourably placed in the division of labour-at the bottom of the symbolic ladder of working roles - can, in day-to-day conversation, claim the status of experts more capable than others of deciding what needs to be done in their activity. Cleaners who dispute the relevance of instructions about the order in which they should carry out office cleaning tasks or about the detergents they should use, may speak in a way that reveals that they see themselves as professionals in the work they do, because they deal with it every day.

Professional rhetoric generally consists of a back-and-forth, and a connection, between advocating an idea of the general interest, the common benefit of the enterprise, which the group perceives itself as representing, and the development of techniques, methods and tools, in which the group sees the mark of a managed activity. As emerges in the second definition, professionalization is thus seen as taking the place of potentially damaging amateur-or even "cowboy"-practices. Professionals see themselves as having the correct understanding of the issues and tested and safe practices for tackling them. Groups that are close to being recognised as professionals obviously press the advantage to the point of claiming authority to legislate on the practices of those whose place within the symbolic division of labour makes them less able to assert this status.

In other words, the dynamics of professionalization are processes in which there is dispute over the terrain of expertise and over the legitimacy to rule on what should be done and how it should be done, at several levels: moral constructions of the world, the efforts of a group to extend the scope of its prerogatives and autonomy. All this leads to a confrontation of points of view, arbitrated by authorities - company management and legal authorities.

In short, what is at play in professionalization is the rivalry between social worlds to define a negotiated order and establish their place in it. The whole process is in dynamic tension and is never entirely frozen: the groups that lack the power to persuade others to recognise them as possessing genuine professional expertise, will inevitably take advantage of circumstances to show that situations which could have turned out badly were rescued, in fact, by their expertise; specialists, ever threatened by the possibility that the relevance of their knowledge will be contested in concrete conditions, will also seek to exploit opportunities to consolidate their legitimacy; middle managers will try to get their position recognised on occasions where the full value of their experience can make itself felt.

\subsection{Specialists Versus Middle Managers}

Working safely or adopting rules that ensure health and safety in the workplace is not an objective reality, but more about the conflict between social worlds over the relevance of those rules. Take the case of butchers working in a supermarket, who 
are subject to a compulsory rule to wear a metal mesh safety glove whenever they cut meat. In any observation of the actual work, it would quickly become clear that there are situations where the butchers fail to wear the glove, to the great displeasure of the safety specialists, who would remind them that there are no exceptions to this rule and no excuses will be accepted. They are very likely to perceive this as the thin end of the wedge, the start of a slippery slope. So, the specialists would see themselves as obliged to turn a deaf ear to the professional arguments, which they see as potentially fallacious. Indeed, the stronger the recriminations, the more convinced they would be that they are right and duty bound not to relent. The butchers, for their part, would be equally sure of being in the right, because of their day-to-day familiarity with the tasks to be done, their experience of the realities and the knowledge they have acquired about the different situations, for example which tasks are easy or difficult, how to handle problems. They would claim that, when you do the job, you know that there are cases where wearing a glove is inefficient and is not necessary because, let us say, there is no risk of injury if the job is done properly.

Working leads to the development of a strong sense that one is ultimately best placed to know how things are and should be. Among workers, the activity gives rise to a professionalization that imparts the feeling that the individual and the group know better than anyone else how people should act and take precautions: this includes the development of know-how not only about self-protection but also about risk. ${ }^{1}$ Conversely, the specialist believes that it is his professional duty not to give way to this rhetoric... even if it means denying other people recognition of their professional skill. In the first half of the 20th Century, work specialists, drawing on the different developments in a science of labour (industrial hygiene and psychotechnical methods, ergonomics...), claimed to act to the benefit of the health and safety of workers, even when opposing those workers' typical working practices. Scientific fields and corporate practices gave rise to a debate between different theories of work (e.g. as a biomechanical operation or an activity). Since the interwar years, a trend towards professionalization has arisen, i.e. the emergence of new professions (psychotechnical...) and towards the construction of knowledge and techniques, in opposition to the knowledge of workers but also of team foremen. In the last 20 years, the movement has intensified, reflecting the themes of industrial and psychosocial risk. With the comeback of issues relating to work, working conditions and workplace health and safety-very salient in the French situation since the 2000s - we seem to be seeing the establishment of a specialised process for managing workplace health and safety within the human resource management function.

Between workers and these specialists stand the middle managers. In the case of the supermarket butchers, this would be a section manager. Both of these social worlds "naturally" expect that the field manager will be on their side: the official

\footnotetext{
${ }^{1}$ See, for example, in the French language literature, the collective defence strategies identified by Dejours (1980) or the know-how of prudence analysed by Cru (2014).
} 
specialists will remind him that it is his job to embody the organisational rules, which take precedence because they have been set by the employer and are carefully considered; the work teams will tell him that he is best placed to see that abstract rules decided by specialists who are unfamiliar with the practical local conditions of operation are not always able to ensure compatibility between the combined demands for both productive efficiency and compliance with safety conditions.

Middle managers are often disparaged in current workplace health and safety policies. Whether they are asked to contribute to policies for reducing stress, diminishing musculoskeletal problems or combating workplace accidents, management and human resource departments see them as being in the frontline. If an accident occurs, they are likely to be blamed for failing to supervise the practices of their teams or to place sufficient stress on safety instructions. The successors of the interwar foreman - operations managers, field managers - are often accused of failing to "notice in time", of lacking expertise in "spotting" (e.g. psychologically fragile employees), or of having poor man-management skills. They are therefore required to undergo training (e.g. in spotting fragile personalities) and to comply with centrally set rules for health and safety management processes. The workplace health and safety policies developed by human resource departments often include central training sessions, seen as the solution for raising awareness of the importance of these matters among middle managers and of ensuring that they apply the related organisational rules to the letter. The aim is to make them reliable agents of the effort to organise work both efficiently and safely. In reality, the way in which companies set their work-related policies is based on implicit theories of work: not only the work done by basic employees, but also by the people who manage them. The role of these managers is conceived as being to relay standards as faithfully as possible. Field managers are seen as the frontline representatives of the organisational systems, with the role of implementing those systems, ensuring that they work properly and improvising final adjustments to guarantee that everything runs smoothly. They are expected to act through meetings with their teams, where they relay the right messages and insist on compliance with procedures.

In this respect, they are not identified as specialists in the work of their staff. Work-related expertise is assumed to be central expertise, of which they are simply the vehicles. The training sessions are precisely the times when, it is supposed, they can assimilate that expertise. Whereas they make daily decisions about the work of their teams and, in so doing, become familiar with that work and with what their staff need to carry out their tasks, they are denied possession of legitimate expertise about the work. Their familiarity with the work is sometimes blamed for reinforcing the tendency of staff to "resist change". To what extent central departments and their functional management tolerate field managers organising (and not simply implementing central organisational plans at local level) therefore lies at the centre of the (disputed) social construction of work policies. What boards and central management departments do with the fact that these middle managers know a lot about the work - about the way day-to-day production challenges are handled- 
because they manage and organise, dictates what role is allocated to field managers in the rival processes of professionalization in the sphere of work policies.

Safety is thus defined in the interplay between territories and powers through which these three groups of actors-basic workers, their line managers and the representatives of the support functions - seek to achieve mutual recognition. By deploying the formal and informal organisational resources that they are able to establish for themselves, each group tries to use its influence to ensure that its construction of the world and its practices gain ascendancy.

\subsection{Middle Management and Functional Departments: The Contested Terrain of the Power to Organise}

This prompts us to introduce a new actor into the analysis: the functional departments, for example human resource departments, to which some of the specialists concerned may be attached. Big integrated companies consist not only of a line management structure, but have also developed a management apparatus that includes support functions. Support functions emerged from the division of corporations into specialist functions, but also from the entry into these areas of professional communities keen to have their specific expertise and necessity recognised. The role of functional departments is to develop the standards and tools that enable such a company to survive as an integrated company, i.e. to harmonise operations and guarantee results. Ultimately, they feel responsible for the fact that the company is properly organised. In this context, their representatives expect the field managers to be the vehicles of this organisation, to "implement" it meticulously.

The support functions do not necessarily have hierarchical power over the field managers. Their power is exercised through the setting of standards, for the purpose of harmonising operations, spreading "good practices", ensuring compliance with legislation and maintaining compatibility between decentralised actions. In the sphere of workplace health and safety, the standards are supposed to create the conditions for productive performance and worker safety. They are designed to organise by providing the best ways for the two objectives to coexist. Field managers are then expected to apply them within their own perimeter of authority.

However, that is not all that the field managers do: they are not passive intermediaries who implement organisational rules. They juggle between organisational principles and rules, on the one hand, and field realities within their sector, on the other. They make adjustments, in the knowledge that organisational rules have to be interpreted and adapted to the real activities of their staff. They accept or reject accommodations with the rules. In short, they end up performing an organising role. In this capacity, they do more than to apply to their own teams the organisational frameworks developed by the support functions; in turn, they also contribute to creating these frameworks and to organising the work of their staff. Through these 
frameworks, staff are protected or exposed (to dangerous machines, to assaults from the public, etc.), the work is made easier or more difficult.

In this face-off between two claims to organise (by the support functions and by the field managers), the tendency in the last 25 years has been for the functional departments to gain increasing power and to gain the ascendancy, for example through technical systems such as IT tools, which impose their underlying formats and rationales.

However, what is in play is the theory of work espoused by health and safety practitioners and field managers: is the aim to comply as closely as possible with requirements that are supposed to guarantee efficiency of production and worker safety; or to develop an activity that needs to be organised, an organisation implemented both by centrally defined rules and instruments and by local adjustments? In the former case, professionalizing health and safety means building up a group of central experts, who will develop tools that operatives and their managers must faithfully implement. In the latter case, professionalizing health and safety means increasing the capacity of field managers to construct organisational solutions that incorporate health and safety preoccupations and know-how of two types: those developed by specialists and those worked out rapidly on a daily basis according to the job and its particular characteristics.

\subsection{Concluding Remarks}

Companies spend a lot of money on safety processes, but the results of those processes are limited. Most of the chapters in this book argue for it to be recognised that, even when perfectly planned, tasks will always be carried out in contexts that require individuals and groups to improvise to varying degrees; workplace health and safety rules cannot be totally fixed in advance without drawing, at least partly, on the knowledge that individuals and groups develop and exchange about the real activity, its risks, its opportunities, and therefore without adapting to actual working cultures. The aim is certainly to improve processes that enable collective structures to continually develop working rules that are simultaneously rules of efficiency and of safety, and are relevant to the situations actually encountered. It is not to argue that working does not require procedures or that only bottom-up procedures are valid: improvisation is also possible within procedures (Johansen et al. 2016; Almklov, in this volume; Gauthereau and Hollnagel 2005). However, it is important that procedures and standards have instrumental value in the situations encountered. As long as they continue to be perceived as foreign to the realities of work, they are not seen as tools and are therefore not spontaneously applied.

It needs to be recognised that the rules set by communities of specialists will not automatically acquire instrumental value for those required to follow them in their work, and that it is not enough to ask the field managers to transmit and rehearse them. As Silvia Gherardi writes in this volume, a safety culture is acquired as part of a community of practice: this is an integral part of sharing professional identity. 
However, it should also be noted that safety rules will not always develop spontaneously in professional cultures, or in the management practices of executives. Referring this time to the suggestion put forward by Rhona Flin, managers may well respond automatically that a good manager will always care about safety, as if there were no need for autonomous thinking or formal conclusions on this specific subject. However, specialised reflection and instruments are not in themselves enough, they need to incorporate communities of practice. Silvia Gherardi, once again, clearly demonstrates that safety rules cannot be learned outside the process of learning to work well. For example, people learn to pay attention to noises as a matter of both skill and self-protection. In Linda Bellamy's contribution, we find the major idea that all this is not purely technical: as a professional doing a job, one first seeks to assimilate the right thing, what one can tell oneself and others is good work, valuable work, even and especially with respect to activities that carry little value in the symbolic division of labour.

What this chapter adds to these ideas is the fact that all this takes place within the power relations specific to today's enterprises. The terrain on which these ideas are propagated is not indifferent to the way in which they reinforce situations or actors, and ask others to evolve in their practices or their power. This does not mean diminishing the status of certain actors to the benefit of others, but changing the terms of the compromises. In power relations within large organisations today, the power exercised by support functions - through the primacy of standards - deprives field managers of a great deal of leeway for action. This power, despite the diversion via participatory management, leaves little room for regular discussion of the relevance of organisational rules. However, rules - in particular safety rules are not purely and simply "implemented": they need to be discussed (what relevance, what correspondence with actual situations and the real problems that those situations occasion; what effectiveness, what degree of validity, what connection with other professional practices?).

What this work argues for would therefore entail two-way information flows: information that not only flows downwards, but also upward flows of information that are rarely incorporated into managerial decision-making, often more taking the form of complaints from field personnel and their managers, criticisms of existing rules and plans, etc. Central management departments need to be able to hear negatives. They need to be able to interpret opposition and debate as something other than resistance to change. This is anything but simple for central management, which feels challenged in its interpretation of the problems and in its construction of solutions, as well as in its authority, when there is resistance at field level.

This would mean companies that tolerate being what they are: spaces in which there is a multiplicity of points of view, between which there is no immediate accord or even a possibility of accord. What can be done for this to be tolerable, given that a company cannot permit disorder? To achieve this, it needs to be accepted that organising, introducing organisation into day-to-day operations, and notably the organisation of safety, is not about implementing organisational rules and letting them operate unchanged for a given time; the issue is organising, a continual activity of organisation. And this is not a task for the departments 
officially dedicated to organisation, with field managers simply required to make minute adjustments, but a continuous process of rule creation very largely taking place among these field managers.

To the positions argued by most of the contributors to this book, this article therefore adds that, in following the recommended paths, companies are faced with a choice, which will determine whether they continue along that route or decide to turn back: a choice about the latitude they should give to their middle managers. They need to develop the capacity of these managers to do something with the complaints of their teams, to analyse the work, its constraints, how the teams go about getting things done, and to make proposals to their line managers and their teams. The key question is therefore how much space today's organisations allow for experiment, for variability, and how much space they give middle managers to construct organisational rules, first of all by holding discussions within their teams and between those teams and support departments. As long as companies lack confidence in the capacity of their managers to conduct debate without creating disorder, there will be no alignment with the positions argued in this volume. Today's big organisations also need to combat their fear that debate is an unproductive waste of time. Governing through centralised rules, through standards, together with communication and training to disseminate them, is an apparently more economical solution than having constantly to construct regulation and support the regular reconstruction of organisational rules. Providing resources especially time - to construct such ways of handling variability is one recommendation that could be made to companies. Reducing the power of support functions and restoring it to field managers is another. This would mean allowing managers to spend time saying things that could be potentially career threatening.

\section{References}

Cru, D. (2014). Le risque et la règle. Le cas du bâtiment et des travaux publics, Toulouse: Erès. Dejours, C. (1980). Travail: usure mentale, republished, Paris: Bayard, 1993.

Gauthereau, V. and Hollnagel, E. (2005). Planning, control and adaptation. European Management Journal, 23(1), 118-131.

Gordon, T., Lahelma, E., Hynninen, P., Metso, T. Palmu, T. and Tolonen, T. (1999). Learning the routines: "professionalization" of newcomers in secondary school, Qualitative Studies in Education, 12(6), 689-705.

Hayes, J. (2014). The role of professionals in managing technological hazards. The Montara blowout. In S. Lockie, D.A. Sonnenfeld and D.R. Fisher (Eds.), Routledge International Handbook of Social and Environmental Change. London \& New York: Routledge.

Johansen, J.P., Almklov, P.G. \& Mohamad, A.B. (2016). What can possibly go wrong? Anticipatory work in space operations. Cognition, Technology and Work, 18(2), 333-350.

Neal, M. and Morgan, J. (2000). The professionalization of everyone? A comparative study of the development of the professions in the United Kingdom and Germany. European Sociological Review, 16(1), 9-26.

Wilensky, H.L. (1964). The professionalization of everyone? American Journal of Sociology, 70 (2), 137-158. 
Open Access This chapter is licensed under the terms of the Creative Commons Attribution 4.0 International License (http://creativecommons.org/licenses/by/4.0/), which permits use, sharing, adaptation, distribution and reproduction in any medium or format, as long as you give appropriate credit to the original author(s) and the source, provide a link to the Creative Commons license and indicate if changes were made.The images or other third party material in this book are included in the book's Creative Commons license, unless indicated otherwise in a credit line to the material. If material is not included in the book's Creative Commons license and your intended use is not permitted by statutory regulation or exceeds the permitted use, you will need to obtain permission directly from the copyright holder.

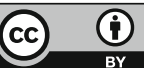

